\title{
2D Finite Element Computer Analysis of Strength for Brazed Joint of Cemented Carbide and Silver Brazing Filler Metal
}

\author{
Meribe Richard Chukwuma ${ }^{1}$, Kazuya MORI ${ }^{1}$, Kento Takenouchi ${ }^{1}$, Yuki Fijishita ${ }^{2}$, Takeshi Eguchi ${ }^{2}$ and Kazufumi \\ Sakata $^{2}$ \\ 1. Kumamoto University, Kurokami 2-39-1, Chuo, Kumamoto \\ 2. Nakayama Seimitsu Co. Ltd.
}

\begin{abstract}
Brazing has a wide acceptance in industries and its simplicity in variety of application attracts more and more patronage. The strength of brazing joint determines the reliability of brazed engineering components. So the need to ascertain the reliability or to predict its failure (without some destructive testing) becomes high even with a computer aided analysis using the Finite Element Analysis. Here, we have employed the services of FEA software, Abaqus CAE, as a tool for the computer calculation to investigate a joint case of cemented carbide brazed with silver-based filler metal. In this paper, 2D analysis has been adopted because the thickness of the material (in 2D) does not influence the final calculation results. We have applied constant loading and constant boundary condition to explore data from the elastic and plastic strain analysis through which we were able to predict the maximum joint strength with respect to the joint thickness. The pattern of the meshing was also significant. And the result could be transferable to a real-life field situation. The final results showed that there is an optimum thickness of the filler metal with the maximum strength which matches that obtained from experiment.
\end{abstract}

Key words: Finite element analysis, brazing, cemented carbide alloy, silver brazing.

\section{Introduction}

In the field of processing using the die, the use of materials with superior wear resistance is an easy method of cutting cost. One of the particularly superior materials is PCD (polycrystalline diamond) with its high heat and wear resistance. PCD is sintered on hard metal, cemented carbide as shown in Fig. 1 with the braze material in the gap. Fig. 2 shows an example of a PCD punch. The strength of the PCD tool depends on the strength of the brazing. The authors obtained relationship of the bending strength with the brazing thickness to study the brazing of the super high alloy, as shown in Fig. 3. The difference between cemented carbide $\circ$ and $\bullet$ is application of

Corresponding author: Meribe Richard Chukwuma, Ph.D. student, research field: reliability and strength of materials. pressure to brazed joint [1]. From the result of experiment, it was understood that strength improves when brazing thickness is more than $25 \mu \mathrm{m}$. In this article, the analysis was based on the phenomenon that joint strength decreases when brazing thickness becomes thin using a finite-element analysis and attention was paid to the extreme difference between the hard metal and the brazing filler material and that was considered.

\section{Finite-Element Analysis}

The authors performed a finite-element analysis in reference to the specimen which was used (as in Fig. 4) for experiment [2]. In experiment, specimens of cantilever bending test of section dimensions, $4 \mathrm{~mm} \times$ $4 \mathrm{~mm}$ were used and, load was applied at the position of $20 \mathrm{~mm}$ from the brazing joint. The mechanical properties of the hard metal (cemented carbide) and 


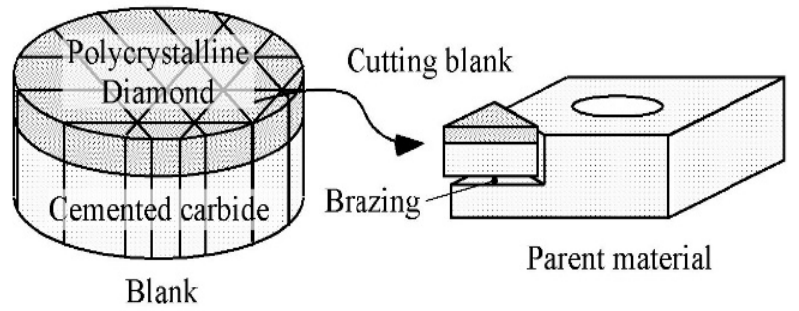

Fig. 1 Manufacturing method of polycrystalline diamond tools.

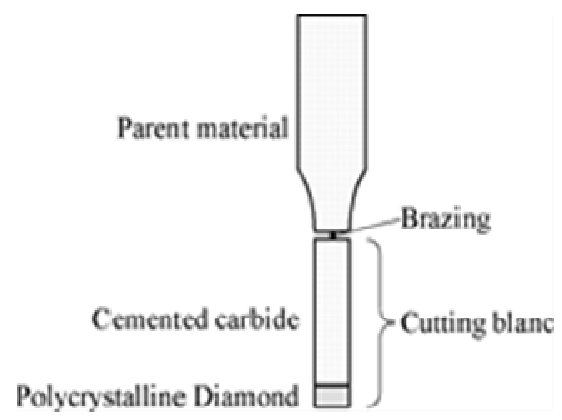

Fig. 2 Application of cemented carbide to punch.

braze material which was used in the experiment is shown in Table 1. This specimen is a bending test specimen for the experiment, but the stress distribution is assumed constant at the upper part of the brazed joint. Therefore, in the finite-element analysis, the load orientation was axial which also created the same effect of tensile stress at the upper part of the brazed joint (area of stress concentration) as it was assumed a model specimen under a tensile force with the boundary condition as shown in Fig. 5. The materials' fixed values in the finite element method are also same as shown in the table of value below (Table 1) same as in experiment. The result of the finite element analysis is shown in Figs. 6 and 7. Fig. 6 expresses the size of the distortion by the light and shade. The deformation of the cemented carbide is too small to understand it from this figure; from the brazed part. It can be understood that the deformation is big. Because of difference of mechanical properties, cemented carbide is 7 times bigger than the silver braze part in a Young's modulus and cemented carbide is 9 times bigger than the silver braze part in a yield stress (proof stress). Fig. 7 shows relations of the biggest strain and brazing thickness of the silver braze material at a stress of $400 \mathrm{MPa}$. The deformation becomes small at brazing thickness of more than 20 $\mu \mathrm{m}$. This relates that strength increased at brazing thickness of more than $25 \mu \mathrm{m}$ in result of experiment of Fig. 3.

\section{Discussions}

Generally, strength is higher if brazing thickness becomes thin [3]. On the other hand, in brazing with

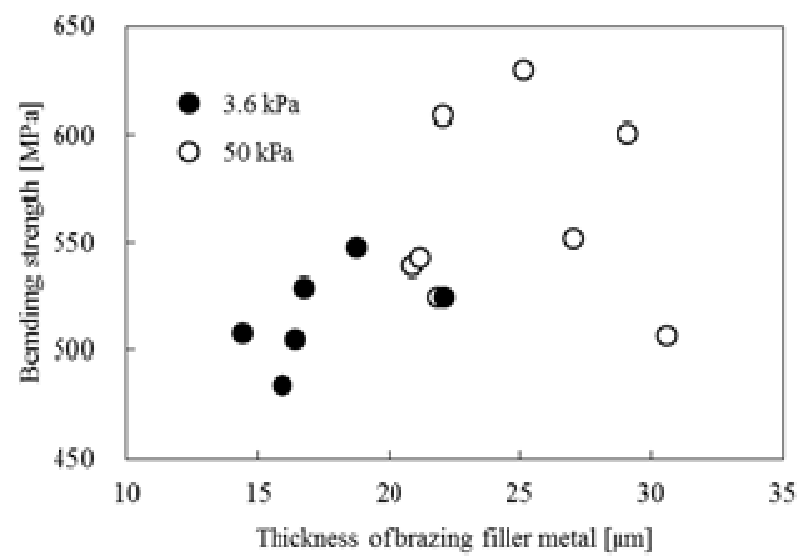

Fig. 3 Bending strength of silver brazing versus brazing thickness.
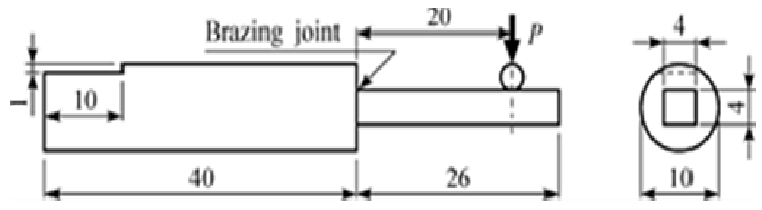

Fig. 4 Cantilever beam specimen (bold line by the plastic deformation at brazing materials in case of thick brazing materials).

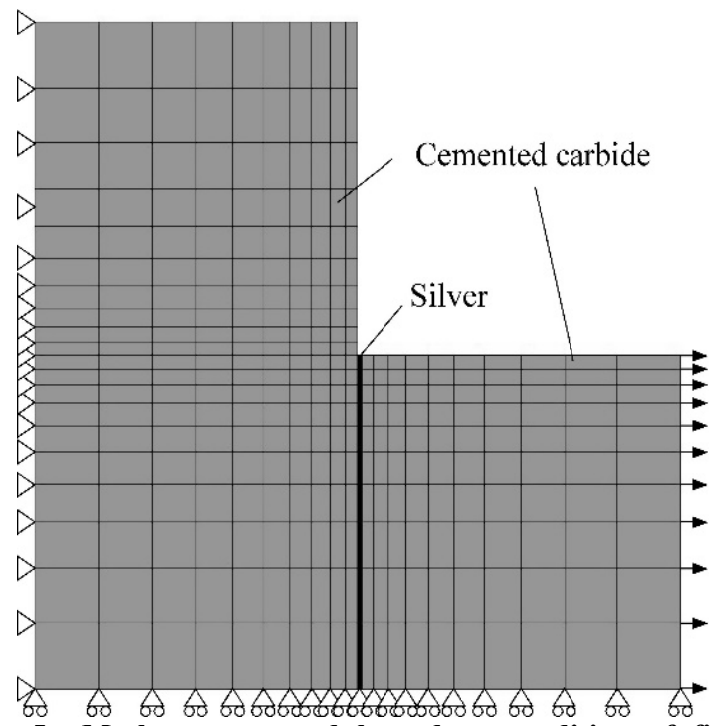

Fig. 5 Mesh pattern and boundary condition of finite element analysis. 

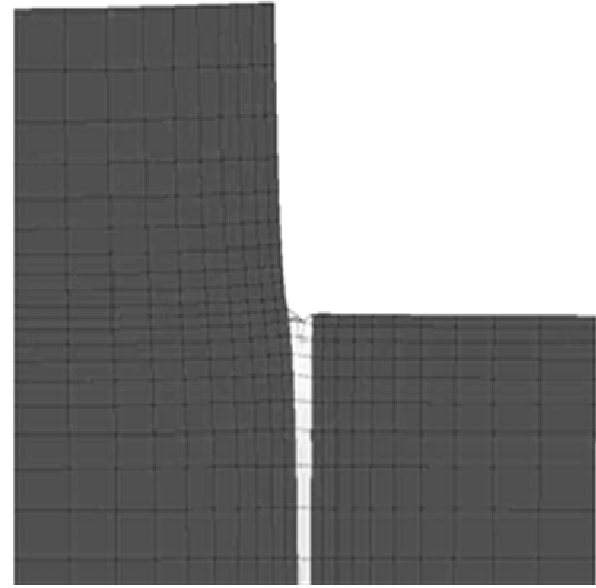

Fig. 6 Strain distribution (grey level represents the magnitude of the strain).

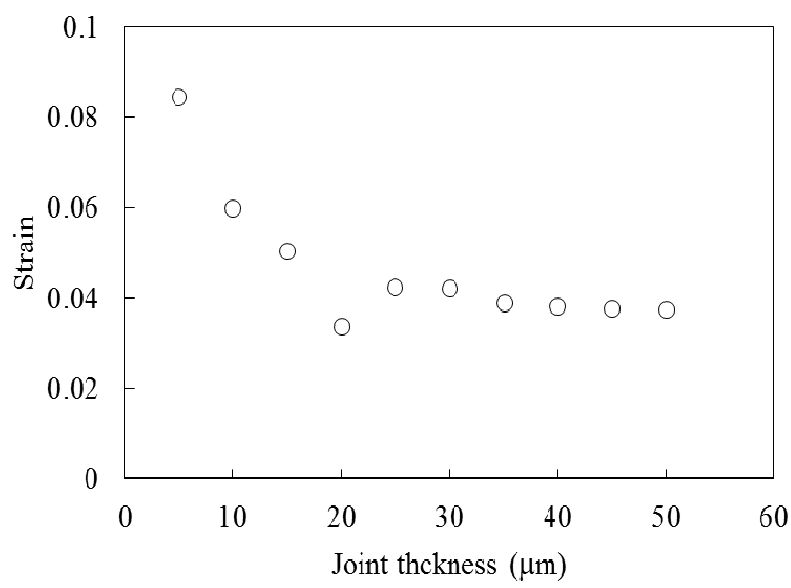

Fig. 7 Strain versus brazing joint thickness.

Table 1 Mechanical property of the brazing filler metal and cemented carbide.

\begin{tabular}{|c|c|c|}
\hline & $\begin{array}{l}\text { Brazing } \\
\text { metal }\end{array}$ & $\begin{array}{c}\text { filler Cemented } \\
\text { carbide }\end{array}$ \\
\hline Young's modulus (Gpa) & 76 & 570 \\
\hline Poisson's ratio [-] & 0.36 & 0.23 \\
\hline Tensile strength (Mpa) & 445 & 1270 \\
\hline $0.2 \%$ proof stress $(\mathrm{MPa})$ & - & 2940 \\
\hline Yield strength (MPa) & 338 & - \\
\hline
\end{tabular}

silver brazing alloy and cemented carbide, strength decreases if brazing thickness is thin. This principle was considered in our investigation. Fig. 8a shows stress distribution when it is a perfectly elastic body and stress redistribution.

It is believed fracture occurred at the point of yield stress that was redistributed in the whole brazing materials. Fig. 8b shows stress distribution (bold line) that occurred when stress on the brazing material

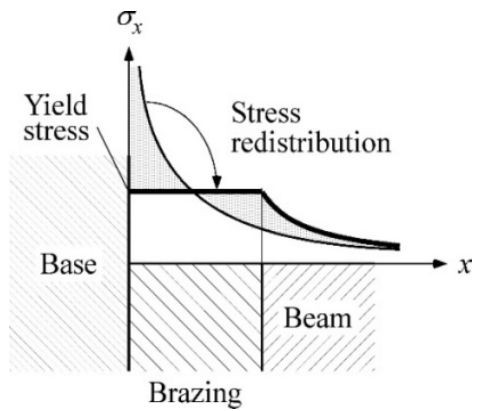

(a) Thick brazing filler

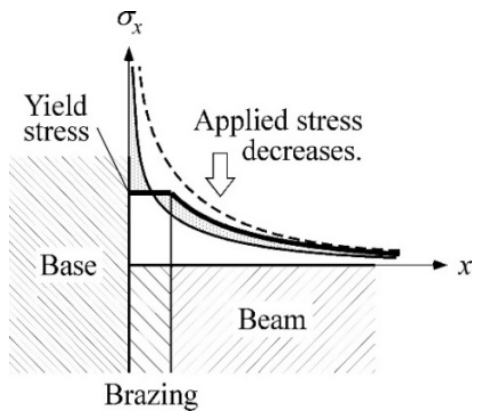

(b) Thin brazing filler

Fig. 8 Stress distributions of brazing filler.

reached the destruction point in case of thin brazing material.

The stress distribution (thin line) is lower than stress distribution in case of thick brazing materials (thin line in Fig. 8a). In other words, brazing materials reach the fracture point in low load if brazing thickness is thinner. It is thought that this phenomenon occurs when the strength of brazing materials is remarkably lower than the strength of base materials.

\section{Conclusions}

Investigation was conducted to verify the phenomenon that strength is increased if higher than a certain point of brazing thickness when brazing with soft silver brazing alloy and cemented carbide. As a result, I got the following conclusions:

(1) The size of the deformation of the hard metal is much smaller than silver braze strain size;

(2) When silver brazing thickness becomes than 20 $\mu \mathrm{m}$, in the finite-element analysis, the size of the deformation goes minimum and becomes constant;

(3) From stress redistribution line at full-scale yield 


\section{Carbide and Silver Brazing Filler Metal}

of brazing, it can be explained why strength increases if brazing thickness goes large until a particular point.

\section{References}

[1] Watanabe, K., Mori, K., Fujishita, Y., Kirihara, K., and Sakata, K. 2013. "High Reliability Brazing Technique on Brazed Joint of Cemented Carbide/Silver Solder." Japan Society of Materials Science Reliability, Destruction Dynamics Combination Symposium Lecture Memoirs:
105-8.

[2] Takenouchi, K., Mori, K., Richard, M., Fujishita, Y., Eguchi, T., and Sakata, K. 2015. "Improvement of Reliability of Brazing Joint on Cemented Carbide Alloy with Low Melting Point Silver Brazing Filler Metal." Japanese Mechanics Kyushu Branch Office Nagasaki Lecture [memoirs].

[3] Association of Japan of welding. JWES joining, welding technology Q\&A1000. http://www-it.jwes.or.jp/qa/details. jsp?pg_no=0080010080. 